Lymphoma

\title{
Ibrutinib plus CIT for R/R mature B-NHL in children (SPARKLE trial): initial safety, pharmacokinetics, and efficacy
}

\author{
G. A. Amos Burke ${ }^{1}$ Auke Beishuizen ${ }^{2}$ - Deepa Bhojwani $\mathbb{D}^{3} \cdot$ Birgit Burkhardt $\mathbb{D}^{4} \cdot$ Véronique Minard-Colin $^{5}$. \\ Robin E. Norris ${ }^{6}$ Edita Kabickova ${ }^{7}$. F. Guclu Pinarli ${ }^{8} \cdot$ Nurdan Tacyildiz $^{9}$ - Angela Howes ${ }^{10}$ - Jan de Jong ${ }^{11}$. \\ Grace Liu $^{12} \cdot$ Kerri Nottage ${ }^{12} \cdot$ Mariya Salman $^{12} \cdot$ Xavier Woot de Trixhe $^{13} \cdot$ Mitchell Cairo $^{14}$
}

Received: 30 September 2019 / Revised: 5 February 2020 / Accepted: 6 February 2020 / Published online: 18 February 2020

(c) The Author(s) 2020. This article is published with open access

Pediatric patients with relapsed/refractory $(\mathrm{R} / \mathrm{R})$ mature $\mathrm{B}$ cell non-Hodgkin lymphoma (B-NHL) have a 2-year overall survival rate with chemoimmunotherapy (CIT) of 15-33\% [1, 2]. Rituximab plus ifosfamide, carboplatin, and etoposide (RICE) is widely used in R/R children with NHL [3] and rituximab plus vincristine, ifosfamide, carboplatin, idarubicin, and dexamethasone (RVICI) has been used in Europe [4, 5].

In preclinical studies, ibrutinib, a Bruton's tyrosine kinase inhibitor approved to treat adults with various B-cell malignancies in the United States and the European Union, among other countries [6], inhibited Burkitt lymphoma (BL; the predominant pediatric mature B-NHL) and diffuse large B-cell lymphoma (DLBCL) tumor cell growth, and prolonged survival in BL xenografted mice [7-10].

Supplementary information The online version of this article (https:// doi.org/10.1038/s41375-020-0749-5) contains supplementary material, which is available to authorized users.

G. A. Amos Burke

amos.burke@addenbrookes.nhs.uk

1 Department of Paediatric Haematology, Oncology and Palliative Care, Cambridge University Hospitals NHS Foundation Trust, Addenbrooke's Hospital, Cambridge, UK

2 Department of Hematology and Oncology, Princess Máxima Center for Pediatric Oncology, Utrecht, Netherlands

3 Children's Center for Cancer and Blood Diseases, Children's Hospital Los Angeles, University of Southern California, Keck School of Medicine, Los Angeles, CA, USA

4 Pediatric Hematology and Oncology, University Hospital Münster, Münster, Germany

5 Department of Child and Adolescent Cancer, Gustave Roussy, Paris, France

6 Department of Pediatrics, University of Cincinnati College of Medicine, Cincinnati Children's Hospital Medical Center, Cincinnati, OH, USA
We report safety, pharmacokinetics, and preliminary efficacy findings from the run-in stage (part 1; December 2016-December 2018) of an ongoing phase 3 trial (SPARKLE).

Of 21 patients with mature B-NHL (median age, 8 years [range, 3-17]; Table 1), 11 received ibrutinib plus modified RICE (RICE modified with dexamethasone) and 10 received ibrutinib plus RVICI (Supplementary Fig. 1). Detailed methods are presented in the Supplementary Appendix, and Supplementary Tables 1 and 2 show the dosing and administration schedule for these treatment regimens. In ibrutinib plus modified RICE and ibrutinib plus RVICI groups, respectively, zero and four $(40.0 \%)$ patients had central nervous system (CNS) disease, three $(27.3 \%)$ and four $(40.0 \%)$ had bone marrow involvement, and one $(9.1 \%)$ and six $(60.0 \%)$ received $>1$ prior line of therapy ( $>1$ relapse).

In ibrutinib plus modified RICE and ibrutinib plus RVICI groups, respectively, median number of treatment

7 Department of Pediatric Hematology and Oncology, Charles University and University Hospital Motol, Prague, Czech Republic

8 Department of Pediatric Oncology, Gazi University, Ankara, Turkey

9 Department of Pediatric Hematology and Oncology, Ankara University, Ankara, Turkey

10 Clinical Oncology, Janssen R\&D LLC, High Wycombe, UK

11 Clinical Pharmacology, Janssen R\&D LLC, San Diego, CA, USA

12 Clinical Oncology, Janssen R\&D LLC, Raritan, NJ, USA

13 Pharmacometrics, Janssen R\&D LLC, Beerse, Belgium

14 Department of Pediatrics, Medicine, Pathology, Microbiology and Immunology and Cell Biology and Anatomy, New York Medical College, Valhalla, NY, USA 
Table 1 Patient demographics and baseline characteristics.

\begin{tabular}{|c|c|c|}
\hline & $\begin{array}{l}\text { Ibrutinib plus } \\
\text { modified RICE } \\
(n=11)\end{array}$ & $\begin{array}{l}\text { Ibrutinib plus RVICI } \\
(n=10)\end{array}$ \\
\hline Median age (range), years & $11.0(3-17)$ & $8.0(4-15)$ \\
\hline \multicolumn{3}{|l|}{ Age group, years, $n(\%)$} \\
\hline $1-5$ & $2(18.2)$ & $2(20.0)$ \\
\hline $6-11$ & $4(36.4)$ & $6(60.0)$ \\
\hline $12-17$ & $5(45.5)$ & $2(20.0)$ \\
\hline \multicolumn{3}{|l|}{ Sex, $n(\%)$} \\
\hline Female & $3(27.3)$ & $1(10.0)$ \\
\hline Male & $8(72.7)$ & $9(90.0)$ \\
\hline \multicolumn{3}{|l|}{ Ethnicity, $n(\%)$} \\
\hline Hispanic or Latino & $2(18.2)$ & 0 \\
\hline Not Hispanic or Latino & $6(54.5)$ & $9(90.0)$ \\
\hline Unknown & $1(9.1)$ & 0 \\
\hline Not reported & $2(18.2)$ & $1(10.0)$ \\
\hline \multicolumn{3}{|l|}{ Race, $n(\%)$} \\
\hline White & $9(81.8)$ & $10(100.0)$ \\
\hline Asian & $1(9.1)$ & 0 \\
\hline Not reported & $1(9.1)$ & 0 \\
\hline \multicolumn{3}{|c|}{ Time from initial diagnosis to first dose of study drug (months) } \\
\hline Mean (SD) & $11.7(10.94)$ & $10.5(6.22)$ \\
\hline Median (range) & $7.0(4-37)$ & $8.2(5-25)$ \\
\hline \multicolumn{3}{|c|}{ Type of mature B-cell NHL at initial diagnosis, $n(\%)$} \\
\hline Burkitt-like lymphoma & $2(18.2)$ & $1(10.0)$ \\
\hline Burkitt lymphoma & $4(36.4)$ & $3(30.0)$ \\
\hline Burkitt leukemia & $2(18.2)$ & $4(40.0)$ \\
\hline $\begin{array}{l}\text { Diffuse large B-cell } \\
\text { lymphoma }\end{array}$ & $3(27.3)$ & 0 \\
\hline $\begin{array}{l}\text { Primary mediastinal B- } \\
\text { cell lymphoma }\end{array}$ & 0 & $1(10.0)$ \\
\hline $\begin{array}{l}\text { High-grade B-cell } \\
\text { lymphoma }\end{array}$ & 0 & $1(10.0)$ \\
\hline Other & 0 & 0 \\
\hline \multicolumn{3}{|l|}{ Extra nodal sites, $n(\%)$} \\
\hline Central nervous system & 0 & $4(40.0)$ \\
\hline Bone marrow & $3(27.3)$ & $4(40.0)$ \\
\hline Other & $9(81.8)$ & $9(90.0)$ \\
\hline \multicolumn{3}{|l|}{ Prior lines of therapy, $n(\%)$} \\
\hline 1 & $10(90.9)$ & $4(40.0)$ \\
\hline$>1$ & $1(9.1)$ & $6(60.0)$ \\
\hline
\end{tabular}

NHL non-Hodgkin lymphoma, SD standard deviation, modified RICE rituximab, ifosfamide, carboplatin, and etoposide, with the addition of dexamethasone, $R V I C I$ vincristine, ifosfamide, carboplatin, idarubicin, that includes dexamethasone.

cycles was 3.0 (range, 1-4) and 2.0 (range, 1-4), and eight and three patients completed $\geq 3$ cycles (Supplementary Fig. 1).

Despite limitations of cross-trial comparisons, including small patient numbers and trial design differences, safety of combined therapies was consistent with known ibrutinib, RVICI, or RICE safety profiles and experience with ibrutinib plus RICE or rituximab, cyclophosphamide, doxorubicin, vincristine, and prednisone in adults with DLBCL [11]. All patients had 1 or more grade $\geq 3$ treatment-emergent adverse events (TEAEs), with $>50 \%$ of patients in either group having hematologic, gastrointestinal, infectious, and metabolism- or nutrition-associated events (Supplementary Table 3). Ten $(90.9 \%)$ patients in ibrutinib plus modified RICE and nine (90.0\%) in ibrutinib plus RVICI groups had serious TEAEs (all grade $\geq 3$ ). Most frequent grade $\geq 3$ ibrutinib-related TEAEs (i.e., those considered related by the investigator) were thrombocytopenia $(42.9 \%)$, neutropenia (38.1\%), anemia (33.3\%), and febrile neutropenia (19.0\%; Supplementary Table 4).

Two patients in ibrutinib plus modified RICE and three in ibrutinib plus RVICI groups had major hemorrhage events (grade $3 / 4$; in the setting of thrombocytopenia; Supplementary Table 5). Two major hemorrhage events (intestinal and intracranial) in the ibrutinib plus RVICI arm were considered ibrutinib related. Major hemorrhage has occurred in $4 \%$ of 2838 ibrutinib-exposed patients in 27 previous clinical trials [12].

Hematologic TEAEs were expected, particularly with background CIT. In a study of 20 children with R/R B-NHL receiving RICE alone, rituximab-related AEs, infections, and hematologic toxicities (e.g., neutrophil- and plateletrelated events) occurred frequently, and one child discontinued because of prolonged myelosuppression [1].

As expected with the CIT regimen [1], bone marrow suppression, reported as laboratory abnormality of low hemoglobin, platelets, or neutrophils, was common (Supplementary Appendix). Hematologic events were generally manageable, most recovering before the next cycle without delaying treatment.

Pharmacokinetic data were assessed for $<12$ years and $\geq 12$ years. For patients aged $12-17$ years $(n=6)$, area under plasma concentration-time curves (AUCs) were within target range $(250-1500 \mathrm{ng} \times \mathrm{h} / \mathrm{mL})$, supporting the $329 \mathrm{mg} / \mathrm{m}^{2} /$ day dose (not exceeding $560 \mathrm{mg}$ daily). However, in younger patients $(n=14)$, AUCs at $329 \mathrm{mg} / \mathrm{m}^{2} /$ day were lower than expected, and $440 \mathrm{mg} / \mathrm{m}^{2} /$ day was required to obtain exposures mostly within target range (Fig. 1). No AUC values were $>1500 \mathrm{ng} \times \mathrm{h} / \mathrm{mL}$ regardless of age or dose. AUC value on cycle 1 day 7 was notably lower than day 1.

Although treatment was scheduled to avoid overlapping ibrutinib and mesna dosing, this was not always possible given prolonged mesna infusion during days 3-9 with RVICI. Mass spectrometric and radiometric analysis of 14C-labeled ibrutinib and mesna, or ifosfamide with metabolizing enzymes, did not show ibrutinib adduct formation or decreased ibrutinib concentrations. Inter- and intraindividual AUC value variability occurred and exceeded variability in adults. Inter-sample discrepancies were potentially introduced by cytochrome P450 subtype 3A inhibitors/inducers (one patient used CYP3A inhibitor, one used CYP3A inducer) before/during ibrutinib treatment (considered a study protocol deviation), ibrutinib 
Fig. 1 Ibrutinib exposures with $240-440 \mathrm{mg} / \mathrm{m}^{2} / \mathrm{day}$ doses. Box/whisker plots of estimated AUC on

pharmacokinetic occasions by cycle and day for each dose for (a) $\mathrm{AUC}_{\tau}$ (estimated AUC of 24-h dosing interval) and (b) $\mathrm{AUC}_{\infty}$ (dose*F/CL; predicted AUC at steady state). Solid line represents median, box represents $25 / 75 \%$, and whiskers represent $10 / 90 \%$ confidence interval. Individual symbols represent outliers. (c) $\mathrm{AUC}_{\tau}$ versus age and (d) versus body surface area. Vertical lines represent individual patients, color represents dose, and symbol represents pharmacokinetic occasion. Target AUC range based on adult exposures was 250-1500 ng $\times \mathrm{h} / \mathrm{mL}$. AUC area under the plasma concentration-time curve.
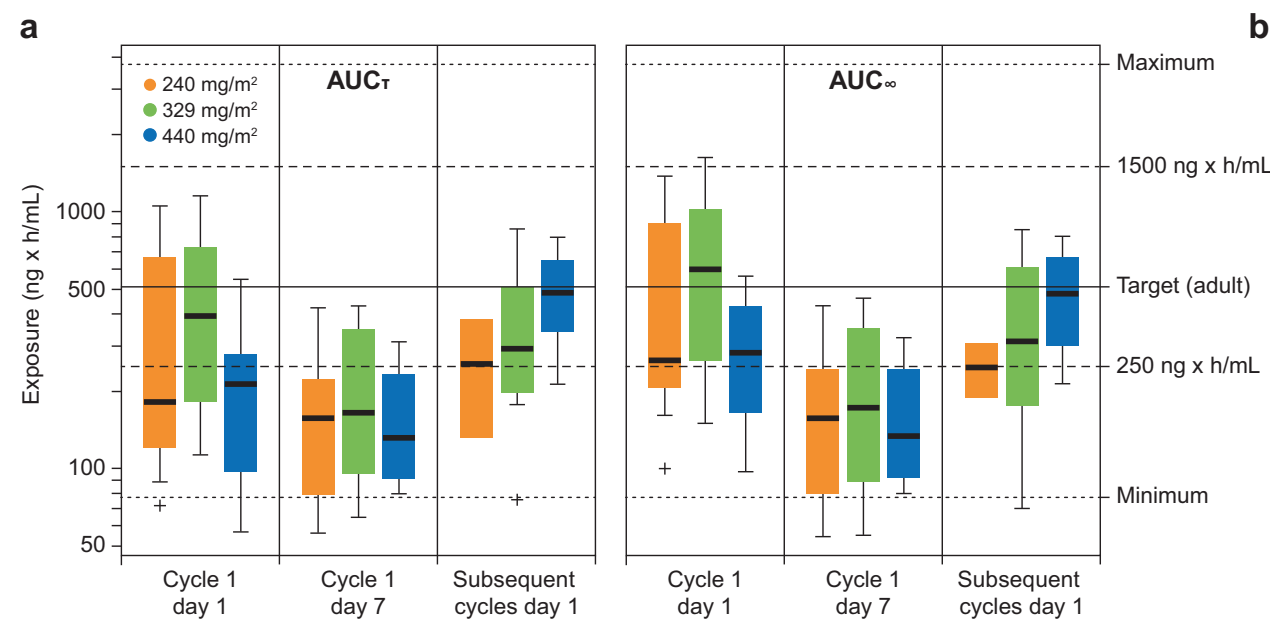

C
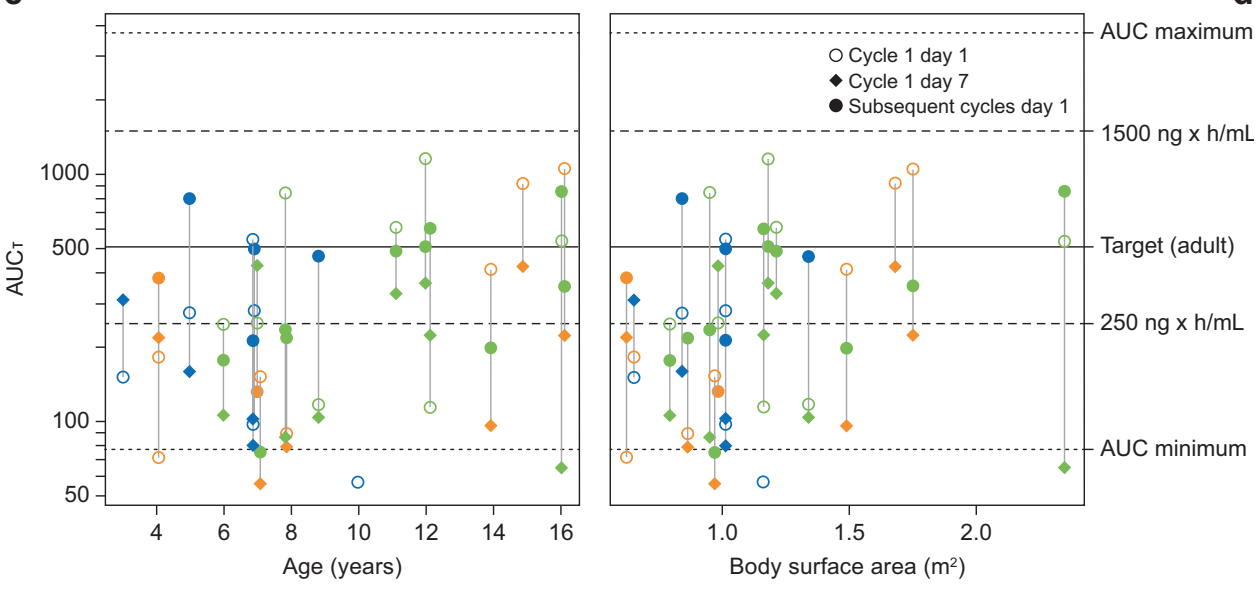

administration via nasogastric tube in some patients, or time and content of food intake differences pre- and postibrutinib administration.

Physiology-based pharmacokinetic simulations using an adult ibrutinib model [13] suggested body surface area-based dosing would result in adult range exposures (Loeckie de Zwart, May 28, 2015, unpublished data). Although the youngest patient was almost 4 years old, a predicted increase in patients aged $<6$ years was uncorroborated. Exposures were still at the low end of the target range, but above observed minimum exposure in adults at $560 \mathrm{mg}$ /day (shown as efficacious in adult B-cell malignancies).

In the ibrutinib plus modified RICE group, there were three progressive disease (PD)-related deaths (one of which was due to multiple organ failure within 30 days of the last dose) and one $\mathrm{AE}$ (septic shock)-related death within 30 days of the last dose occurred. In the ibrutinib plus RVICI group, three TEAE-related deaths (unrelated to ibrutinib; within 30 days of last dose; two due to sepsis and one because of neutropenic sepsis) and six PD-related deaths occurred. Most of these patients had multiply relapsed disease and were heavily pretreated pre-enrollment; therefore, they had poor hematologic reserve and were highly susceptible to complications due to therapy.

Preliminary efficacy findings were promising. As prognosis for this pediatric patient population is poor, achieving a complete response (CR) to proceed to high-dose consolidative therapy is important [1]. Of 21 patients who received $\geq 1$ dose of ibrutinib, $12(57.1 \%)$ experienced a response. In the ibrutinib plus modified RICE group, eight $(72.7 \%)$ were responders, among whom three $(27.3 \%)$ had a $\mathrm{CR}$, including one unconfirmed CR (one DLBCL, one BL, one Burkitt leukemia [B-AL]), and five (45.5\%) had a partial response (PR; one BL, two DLBCL, two Burkitt-like lymphoma). In the ibrutinib plus RVICI group, four $(40.0 \%)$ were responders, among whom two (20\%) had a CR (both B-AL) and two had a PR (one B-AL, one highgrade B-cell lymphoma). Across both groups, all responders received treatment at first relapse, except one with highgrade B-cell lymphoma in the ibrutinib plus RVICI arm who achieved PR in second relapse.

Among 14 patients treated after first relapse, 11 (78.6\%) were responders (five $\mathrm{CR}$, six $\mathrm{PR}$ ), and one of seven 
$(14.3 \%)$ treated after second relapse was a responder (one PR). Supplementary Table 6 presents response by histology. Although this part of the study was not designed to compare efficacy of either regimen, overall response and CR rates were higher with ibrutinib plus RICE than ibrutinib plus RVICI. At an 18-month median follow-up, median investigator-assessed event-free survival (EFS) was unreached in the ibrutinib plus modified RICE group and 2.4 months in the ibrutinib plus RVICI group (Supplementary Fig. 2), potentially because more patients treated with the latter had received $>1$ prior line of therapy. Treatment at first relapse (versus second relapse) was associated with a higher response rate and longer EFS possibly because patients tolerated therapy better and did not discontinue prematurely due to AEs. In addition, unlike those in the ibrutinib plus RICE group, some patients in the ibrutinib plus RVICI arm had CNS involvement, and therefore a poorer overall prognosis. Given the exploratory nature of the EFS analysis and small sample size, it is difficult to ascertain whether the addition of ibrutinib to CIT is beneficial and results should be interpreted with caution.

Seven patients subsequently received hematopoietic stem cell transplantation (HSCT; four in the ibrutinib plus modified RICE group and two in the ibrutinib plus RVICI arm after completing $\geq 3$ treatment cycles, and one after completing two cycles of ibrutinib plus RVICI and one cycle of ibrutinib monotherapy; Supplementary Fig. 1).

Results of part 1 of the trial support the continued assessment of ibrutinib with modified RICE/RVICI in this patient population. Part 2 is assessing the efficacy of ibrutinib $\left(329 \mathrm{mg} / \mathrm{m}^{2} /\right.$ day in patients aged $\geq 12$ years and 440 $\mathrm{mg} / \mathrm{m}^{2} /$ day in patients aged $<12$ years) plus modified RICE/ RVICI versus modified RICE/RVICI CIT alone in a randomized fashion. Pharmacokinetic sampling in part 2 is on day 15 instead of day 7 of cycle 1 to avoid potential interactions. Because preliminary efficacy findings were better in patients treated upon first relapse, the protocol was amended to only include patients in first relapse. Due to the very poor prognosis for pediatric patients with $R / R$ mature B-NHL, trials such as this, while challenging to conduct, are critically important.

Acknowledgements Sponsored by Janssen Research \& Development, LLC. Support for pharmacokinetic and pharmacodynamic assessments was provided by Martine Neyens and Sriram Balasubramanian, respectively, Janssen Research \& Development, LLC. Additional data quality control and manuscript review were provided by Madeliene Curtis, Janssen Research \& Development, LLC. Writing assistance was provided by Liqing Xiao and Sally Hassan of Parexel and funded by Janssen Global Services, LLC. The authors would also like to thank the patients who participated in this trial, and their families, as well as the investigators, study coordinators, study teams, and nurses.

Author contributions $\mathrm{GAAB}, \mathrm{AB}, \mathrm{BB}, \mathrm{MC}, \mathrm{VM}-\mathrm{C}, \mathrm{AH}, \mathrm{JdJ}, \mathrm{KN}$, and MS designed the study. EK, MC, BB, KN, and MS collected and assembled data. VM-C, EK, FGP, and NT provided study material or patients. GAAB, AB, BB, MC, DB, REN, AH, JdJ, GL, XWdT, KN, and MS analyzed and interpreted data. All authors wrote and/or critically revised the manuscript for important intellectual content, provided final approval of the manuscript, and are accountable for all aspects of the work.

\section{Compliance with ethical standards}

Conflict of interest GAAB has received consultancy fees from Janssen, Merck, Takeda, and Roche. BB did not receive personal fees, but her institution received consultancy fees from Janssen, Roche, ADC Therapeutics, Novartis, and Celgene. AH, JdJ, KN, and MS hold Johnson \& Johnson stock and are employed by Janssen R\&D. GL and $\mathrm{XWdT}$ are also employees of Janssen. MC has received research funding from Janssen. AB, DB, VM-C, REN, EK, FGP, and NT have no conflicts of interest to disclose.

Publisher's note Springer Nature remains neutral with regard to jurisdictional claims in published maps and institutional affiliations.

Open Access This article is licensed under a Creative Commons Attribution 4.0 International License, which permits use, sharing, adaptation, distribution and reproduction in any medium or format, as long as you give appropriate credit to the original author(s) and the source, provide a link to the Creative Commons license, and indicate if changes were made. The images or other third party material in this article are included in the article's Creative Commons license, unless indicated otherwise in a credit line to the material. If material is not included in the article's Creative Commons license and your intended use is not permitted by statutory regulation or exceeds the permitted use, you will need to obtain permission directly from the copyright holder. To view a copy of this license, visit http://creativecommons. org/licenses/by/4.0/.

\section{References}

1. Griffin TC, Weitzman S, Weinstein H, Chang M, Cairo M, Hutchison R, et al. A study of rituximab and ifosfamide, carboplatin, and etoposide chemotherapy in children with recurrent/ refractory B-cell (CD20+) non-Hodgkin lymphoma and mature B-cell acute lymphoblastic leukemia: a report from the Children's Oncology Group. Pediatr Blood Cancer. 2009;52:177-81.

2. Cairo M, Auperin A, Perkins SL, Pinkerton R, Harrison L, Goldman S, et al. Overall survival of children and adolescents with mature B cell non-Hodgkin lymphoma who had refractory or relapsed disease during or after treatment with $\mathrm{FAB} / \mathrm{LMB}$ 96: a report from the FAB/LMB 96 study group. $\mathrm{Br} \mathrm{J}$ Haematol. 2018;182:859-69.

3. Egan G, Goldman S, Alexander S. Mature B-NHL in children, adolescents and young adults: current therapeutic approach and emerging treatment strategies. Br J Haematol. 2019;185:1071-85.

4. Woessmann W, Zimmermann M, Burkhardt B, Meinhardt A, Rosenbusch C, Vaillant V, et al. Relapsed or refractory Burkitt lymphoma in children and adolescents after BFM-type first-line therapy-a BFM group report. Blood. 2014;124:1738.

5. Woessmann W, Zimmermann M, Meinhardt A, Müller S, Hauch H, Knörr F, et al. Progressive or relapsed Burkitt lymphoma or leukemia in children and adolescents after BFM-type first-line therapy. Blood. 2020. https://doi.org/10.1182/blood.2019003591 [Epub ahead of print].

6. Gayko U, Fung M, Clow F, Sun S, Faust E, Price S, et al. Development of the Bruton's tyrosine kinase inhibitor ibrutinib for B cell malignancies. Ann NY Acad Sci. 2015;1358:82-94. 
7. Chu Y, Lee S, Shah T, Yin C, Barth M, Miles RR, et al. Ibrutinib significantly inhibited Bruton's tyrosine kinase (BTK) phosphorylation, in-vitro proliferation and enhanced overall survival in a preclinical Burkitt lymphoma (BL) model. Oncoimmunology. 2019;8:e1512455.

8. Davis RE, Ngo VN, Lenz G, Tolar P, Young RM, Romesser PB, et al. Chronic active B-cell-receptor signalling in diffuse large Bcell lymphoma. Nature. 2010;463:88-92.

9. Schaffer M, Chaturvedi S, Davis C, Aquino R, Stepanchick E, Versele $\mathrm{M}$, et al. Identification of potential ibrutinib combinations in hematological malignancies using a combination highthroughput screen. Leuk Lymphoma. 2018;59:931-40.

10. Advani RH, Buggy JJ, Sharman JP, Smith SM, Boyd TE, Grant $\mathrm{B}$, et al. Bruton tyrosine kinase inhibitor ibrutinib (PCI-32765) has significant activity in patients with relapsed/refractory B-cell malignancies. J Clin Oncol. 2013;31:88-94.

11. Sauter CS, Verwys SL, McCall SJ, Miller ST, Courtien AI, Schoder $\mathrm{H}$, et al. Phase I study combining ibrutinib with rituximab, ifosfamide, carboplatin, and etoposide (R-ICE) in patients with relapsed or primary refractory diffuse large B-cell lymphoma (DLBCL): NCI-Cancer Therapeutics Evaluation Program (CTEP) \#9588. Blood. 2016;128(Suppl 1):4198. abstract 4198.

12. IMBRUVICA (ibrutinib). [Prescribing information]. Horsham, PA: Pharmacyclics LLC; Sunnyvale, CA: Janssen Biotech, Inc; 2018.

13. de Zwart L, Snoeys J, De Jong J, Sukbuntherng J, Mannaert E, Monshouwer M. Ibrutinib dosing strategies based on interaction potential of CYP3A4 perpetrators using physiologically based pharmacokinetic modeling. Clin Pharm Ther. 2016;100:548-57. 